\title{
Hemodynamic effects of enhanced external counterpulsation on cerebral arteries: a multiscale study
}

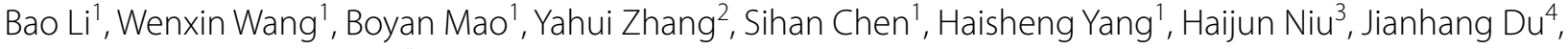 \\ Xiaoling Li ${ }^{4}$ and Youjun Liü ${ }^{1 *}$
}

*Correspondence:

lyjlma@bjut.edu.cn

${ }^{1}$ Department of Biomedical Engineering, College of Life

Science and Bioengineering, Beijing University

of Technology, No. 100 Pingleyuan, Chaoyang

District, Beijing 100124, China Full list of author information is available at the end of the article

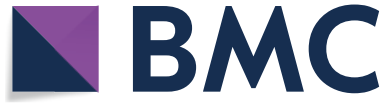

(c) The Author(s) 2019. This article is distributed under the terms of the Creative Commons Attribution 4.0 International License (http://creativecommons.org/licenses/by/4.0/), which permits unrestricted use, distribution, and reproduction in any medium, provided you give appropriate credit to the original author(s) and the source, provide a link to the Creative Commons license, and indicate if changes were made. The Creative Commons Public Domain Dedication waiver (http://creativecommons.org/publicdomain/zero/1.0/) applies to the data made available in this article, unless otherwise stated.
Methods: A zero-dimensional/three-dimensional (0D/3D) geometric multiscale model of the cerebral artery was established to obtain acute hemodynamic indicators, including mean arterial pressure (MAP) and cerebral blood flow (CBF), as well as localized hemodynamic details for the cerebral artery, which includes wall shear stress (WSS) and oscillatory shear index (OSI). Counterpulsation was achieved by applying pressure on calf, thigh and buttock modules in the 0D model. Different counterpulsation modes including various pressure amplitudes and pressurization durations were applied to investigate hemodynamic responses, which impact acute and long-term treatment effects. Both vascular collapse and cerebral autoregulation were considered during counterpulsation.

Results: Variations of pressure amplitude and pressurization duration have different impacts on hemodynamic effects during EECP treatment. There were small differences in the hemodynamics when similar or different pressure amplitudes were applied to calves, thighs and buttocks. When increasing pressure amplitude was applied to the three body parts, MAP and CBF improved slightly. When pressure amplitude exceeded $200 \mathrm{mmHg}$, hemodynamic indicators almost never changed, demonstrating consistency with clinical data. However, hemodynamic indicators improved significantly with increasing pressurization duration. For pressurization durations of $0.5,0.6$ and $0.7 \mathrm{~s}$, percentage increases for MAP during counterpulsation were 1.5\%, 23.5\% and 39.0\%, for CBF were $1.2 \%, 23.4 \%$ and $41.6 \%$ and for time-averaged WSS were $0.2 \%, 43.5 \%$ and $85.0 \%$, respectively.

Conclusions: When EECP was applied to patients with cerebral ischemic stroke, pressure amplitude applied to the three parts may remain the same. Patients may not gain much more benefit from EECP treatment by excessively increasing pressure amplitude 
above $200 \mathrm{mmHg}$. However, during clinical procedures, pressurization duration could be increased to $0.7 \mathrm{~s}$ during the cardiac circle to optimize the hemodynamics for possible superior treatment outcomes.

Keywords: Enhanced external counterpulsation, Cerebral artery, Geometric multiscale model, Mean arterial pressure, Cerebral blood flow, Wall shear stress

\section{Background}

Enhanced external counterpulsation (EECP) is a noninvasive clinical method which is recommended by the US Food and Drug Administration (FDA) for treatment of cardio-cerebrovascular disease [1]. EECP uses cuffs to mechanically compress the human lower body and increase diastolic blood pressure (DBP) while decreasing compression at the onset of systole and decreasing vascular resistance to reduce the intra-aortic systolic blood pressure (SBP) [2]. By improving blood circulation, EECP assists cardiac function while increasing blood perfusion in the heart, and brain, as well as the kidneys and other organs [3]. This is a common method for the treatment of cerebral ischemic stroke which is globally applied [4-7].

The basic principle of EECP treatment is to significantly increase DBP and form a double-pulse blood perfusion mode for cerebral blood vessels, thus improving cerebral blood flow (CBF). EECP can effectively increase blood perfusion in the brains of patients with ischemic stroke while alleviating ischemia symptoms, which are the acute hemodynamic effects of treatment, in real time. In addition, by accelerating blood flow, EECP significantly improves wall shear stress (WSS) in cerebral arteries. For stenotic cerebral arteries, vascular endothelial cells (VECs) of stenosis are constantly exposed to a high WSS environment throughout the long-term application of EECP, effectively inhibiting atherosclerosis development and promoting the benign remodeling of blood vessels [8]. While the long-term effects of vascular remodeling are complex and do not depend on any single factor, WSS is a clinically recognized indicator which significantly impacts the remodeling and inhibits the development of atherosclerosis. Research has shown that high WSS can promote growth in collateral vessels which have stopped growing, thus significantly increasing numbers of new microvessels in the stenotic region [9]. Therefore, when vascular stenosis occurs, local high WSS in the plaque promotes the formation of microcirculatory vessels, leading to blood perfusion in the ischemic region through the separation of blood flow.

However, further research [10-14] demonstrates that low WSS $(<1 \mathrm{~Pa})$ may promote the development of plaque, while excessive WSS ( $>7 \mathrm{~Pa})$ can make plaque unstable and vulnerable to rupture. Moderately high WSS $(1<$ WSS $<7 \mathrm{~Pa})$ may affect vascular endothelial cell gene expression, promote cell growth and energy metabolism, decrease intracellular lipid deposition, as well as decrease cell adhesion and immune inflammatory response. WSS has the function of protecting the endothelial layer and promoting repair of damaged blood vessels. As a result, moderately high WSS is beneficial for the benign remodeling of stenotic vessels and inhibiting the development of atherosclerosis. As well as WSS, high oscillatory shear index (OSI) is also a predictor of atherosclerosis and vulnerable plaque $[15,16]$. It is a hemodynamic indicator that reflects backflow. Higher OSI means more backflow, which can cause the formation of vascular plaques and lesions. OSI can be calculated as follows: 


$$
\mathrm{OSI}=\frac{1}{2}\left(1-\frac{\left|\int_{0}^{T} \overrightarrow{\tau_{\omega}} \mathrm{d} t\right|}{\int_{0}^{T}\left|\overrightarrow{\tau_{\omega}}\right| \mathrm{d} t}\right)
$$

where $\tau_{\omega}$ is WSS and $T$ is the cardiac cycle. In contrast, the lower OSI is beneficial to benign remodeling of stenotic vessels. There are some areas in the cerebral arteries that have pronounced curves and a large angle of torsion, such as cerebral part of the internal carotid artery and the posterior communicating artery, among others. These tend to be the high incidence areas of cerebral artery plaques and aneurysms, as blood flow moves both in the anterograde and in the retrograde directions in the curved vessels, while OSI increases, which promotes the development of atherosclerosis [17]. In addition, wall shear stress gradient (WSSG) also affects the remodeling of the vascular endothelial layer. Positive WSSG inhibits both proliferation and apoptosis of vascular endothelial cells; negative WSSG promotes proliferation and apoptosis of cells [18]. Treatment effects of EECP acting on VECs are long-term hemodynamic effects. Both acute and long-term hemodynamic effects are primary mechanisms of EECP treatment for stroke patients.

Numerous clinical reports and animal experiments have demonstrated the hemodynamic effects of EECP on cerebral arteries. Xiong and Lin compared the velocity waveforms of middle cerebral artery flow in patients with stroke before and during counterpulsation. They found that diastolic blood flow of the cerebral artery significantly increased during counterpulsation [19-22]. Using an animal experiment, Zhang and colleagues observed that long-term application of EECP reversed the progression of high cholesterol and caused benign remodeling of cerebral arteries. Zhang concluded that WSS was the major factor for promoting restoration and remodeling [8]. These studies have shown that the hemodynamic effects of EECP were effective for the treatment of ischemic stroke disease. However, due to patients' physiological differences, a phenomenon often occurs in which the same counterpulsation mode may result in different effects for different patients in clinical treatment [21]. This means that the counterpulsation mode should be appropriately adjusted for different stroke patients to optimize treatment. Based on the actual operation of clinical EECP equipment, the adjustable counterpulsation modes include pressure amplitudes and pressurization durations of cuffs wrapped around calves, thighs and buttocks. According to clinical surveys, EECP devices that have been manufactured by different companies may have differing modes of operation. Some EECP devices always maintain the same pressure amplitude for the three body parts, but pressure can be adjusted [23]. However, some devices only use one pressure amplitude and so apply the same pressure to the three parts. Therefore, for clinical treatment of stroke patients, three questions must be answered: (1) During counterpulsation, should the same pressure amplitude be applied to the three body parts? (2) How can pressure amplitude applied to each part be adjusted? (3) How can pressurization duration of counterpulsation be adjusted?

When focusing on the concerns of clinical applications, it is necessary to design a simple, rapid method to obtain responses for acute hemodynamic indicators and localized hemodynamic details of the cerebral arteries to EECP. This study initially used a geometric multiscale numerical $0 \mathrm{D} / 3 \mathrm{D}$ model of the cerebral artery-blood circulatory 
Table 1 Variations of acute indicators between experimental and control groups

\begin{tabular}{ccccccccc}
\hline & $\begin{array}{c}\text { Pressure } \\
\text { of calves }\end{array}$ & $\begin{array}{l}\text { Pressure } \\
\text { of thighs }\end{array}$ & $\begin{array}{l}\text { Pressure } \\
\text { of buttocks }\end{array}$ & $\begin{array}{l}\text { Pressure } \\
\text { difference }\end{array}$ & MAP & CBF & $\begin{array}{l}\text { Percentage } \\
\text { of increase } \\
\text { in MAP (\%) }\end{array}$ & $\begin{array}{l}\text { Percentage } \\
\text { of increase } \\
\text { in CBF (\%) }\end{array}$ \\
\hline $\begin{array}{c}\text { Control } \\
\text { group }\end{array}$ & 0 & 0 & 0 & & 85.08 & 12.10 & & \\
$\begin{array}{c}\text { Experiment } \\
\text { groups }\end{array}$ & 200 & 200 & 200 & 0 & 115.34 & 16.45 & 35.57 & 35.95 \\
& 210 & 200 & 190 & 10 & 115.44 & 16.47 & 35.68 & 36.12 \\
& 220 & 200 & 180 & 20 & 115.54 & 16.49 & 35.80 & 36.28 \\
& 230 & 200 & 170 & 30 & 115.67 & 16.52 & 35.95 & 36.53 \\
& 240 & 200 & 160 & 40 & 115.75 & 16.53 & 36.05 & 36.61 \\
\hline
\end{tabular}

Pressure unit: $\mathrm{mmHg}$, flow rate unit: $\mathrm{mL} / \mathrm{s}$

$M A P$ mean arterial pressure, $C B F$ cerebral blood flow

system to explore hemodynamic effects of different counterpulsation modes on cerebral arteries. The geometric multiscale method is a special strategy that simulates the blood circulatory system. This method uses different models to simulate different parts of the circulatory system [24-26]. The three-dimensional (3D) model can be used to observe the hemodynamic environment of the cerebral artery with localized details, which determine long-term hemodynamic effects. The lumped parameter (OD) model could be used to simulate acute hemodynamic effects during the application of EECP. Characteristics of the geometric multiscale model mean it is suitable for hemodynamic simulation of EECP, as the localized hemodynamic details in the 3D model can observed in real time when counterpulsation is applied to the OD model. The mean arterial pressure (MAP) and $\mathrm{CBF}$, which are the clinical indicators commonly used to evaluate acute hemodynamic effects on patients with cerebral ischemic stroke, can be calculated using a OD model, while the localized hemodynamic environment, including changes to WSS and OSI that significantly affect the long-term hemodynamic effects, can be observed with the 3D model.

This study aimed to establish a geometric multiscale method to explore acute and long-term hemodynamic effects on the cerebral artery caused by EECP. The effectiveness of our model was examined by comparing simulation results with clinical data. Following simulation of different counterpulsation modes, optimal strategies for EECP treatment mode were suggested for patients with cerebral ischemic stroke.

\section{Results}

Influence of the same and different pressure amplitudes of each part

MAP is the clinical indicator typically used to evaluate the acute effects on cerebral ischemic stroke, and CBF is the most direct indicator to reflect blood perfusion of cerebrovascular vessels. Both of these are acute hemodynamic indicators. To answer the clinical question about whether similar or different pressure amplitudes at calves, thighs and buttocks should be maintained, numerical simulations were conducted. Results of MAP and CBF, which can be seen in Table 1 and Fig. 1, show there was little difference between each experimental group. The acute hemodynamic indicators increased slightly as the pressure difference was increased for each body part. 

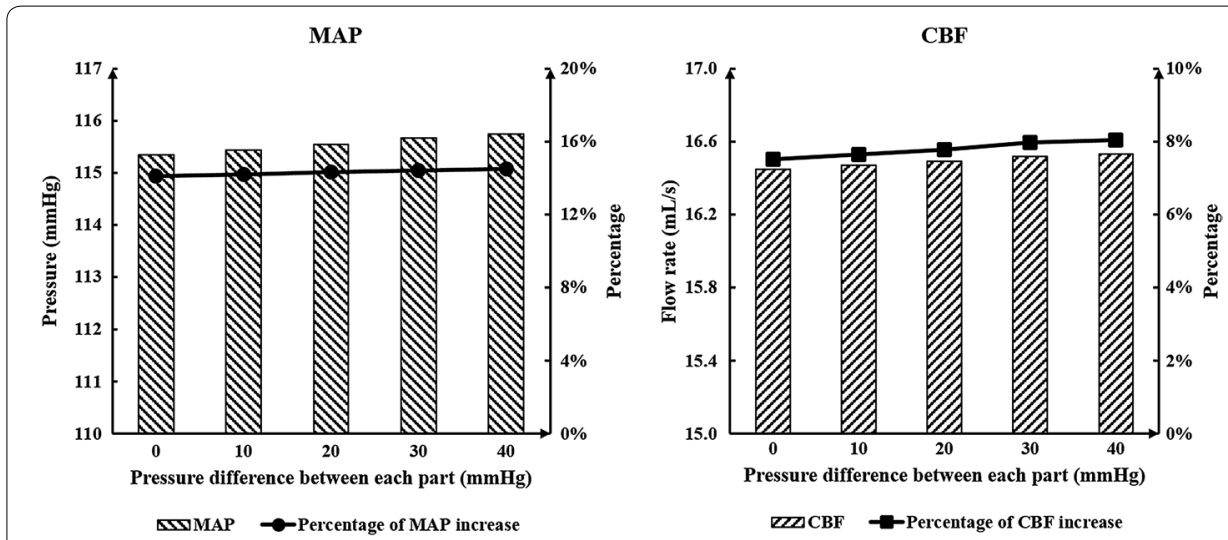

Fig. 1 Calculated MAP and CBF of simulated experimental results of various pressure amplitude differences among the three body parts. MAP is mean arterial pressure and CBF is cerebral blood flow

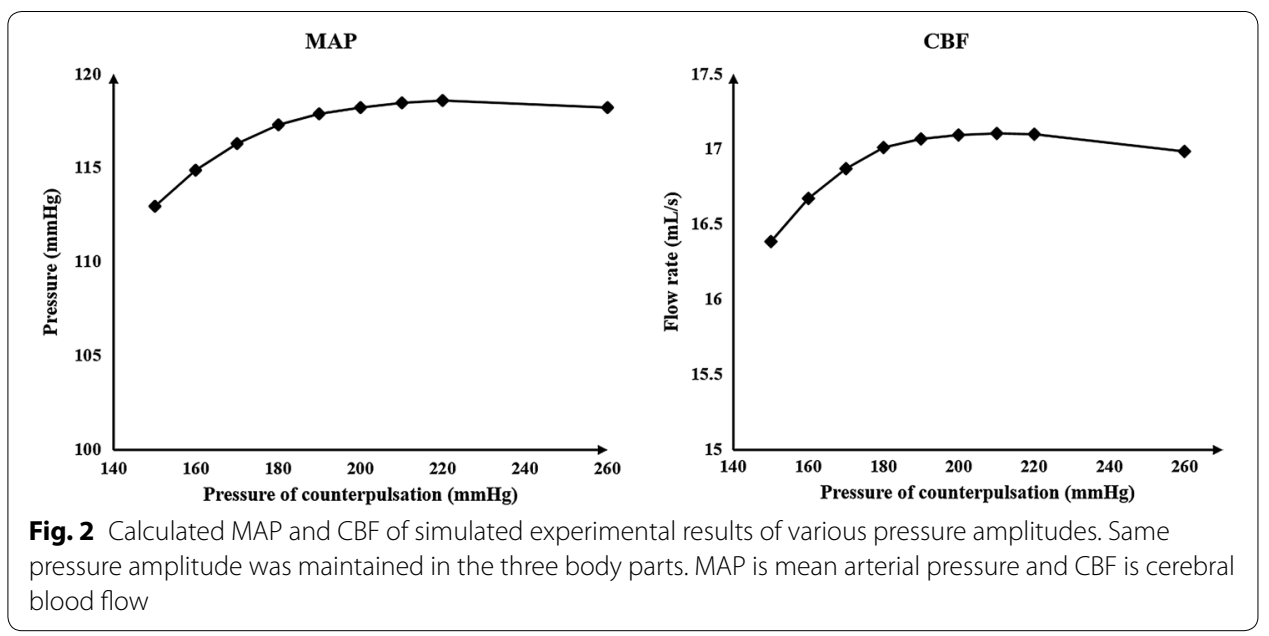

Influence of the pressure amplitudes of the three parts

It can be concluded from the above results that using both the same and different pressure amplitudes for each part resulted in nearly the same acute hemodynamic effects and thus caused almost the same long-term effects. Therefore, we conducted a series of numerical experiments with different pressure amplitudes while maintaining the same pressure in the three body parts. Calculated MAP and CBF values are shown in Fig. 2. Figure 3 demonstrates the simulation waveforms of the area-averaged WSS under pressure amplitudes of 150, 200 and $260 \mathrm{mmHg}$ in the three body parts. The time points of maximum WSS during systole and diastole were 0.13 and $0.5 \mathrm{~s}$, respectively, while the minimum time point during a cardiac circle was $0.0 \mathrm{~s}$. WSS contours of the cerebral artery at each extremum time point are shown in Fig. 4. During systole, time-averaged WSS (TAWSS) under the three pressure amplitudes was 1.826, 1.875 and $1.839 \mathrm{~Pa}$, while during diastole, TAWSS was $1.646,1.818$ and $1.843 \mathrm{~Pa}$, respectively. These results suggest that when the pressure amplitude of the three parts was less than $200 \mathrm{mmHg}$, both MAP and CBF increased slightly with the increasing pressure amplitude. WSS had a very slight increase during diastole and almost no variation during systole despite increasing 


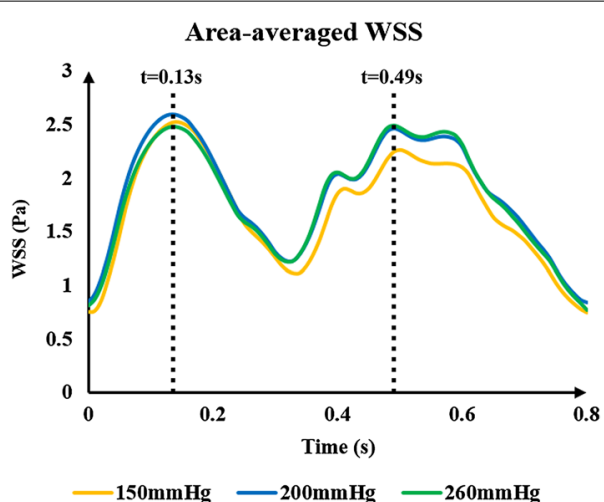

Fig. 3 Area-averaged WSS waveforms of simulated experimental results of three pressure amplitudes. The same pressure amplitude was maintained in the three body parts; $0.13 \mathrm{~s}$ was the maximum time point during systolic phase, and $0.49 \mathrm{~s}$ was the maximum time points during diastolic phase. WSS is wall shear stress

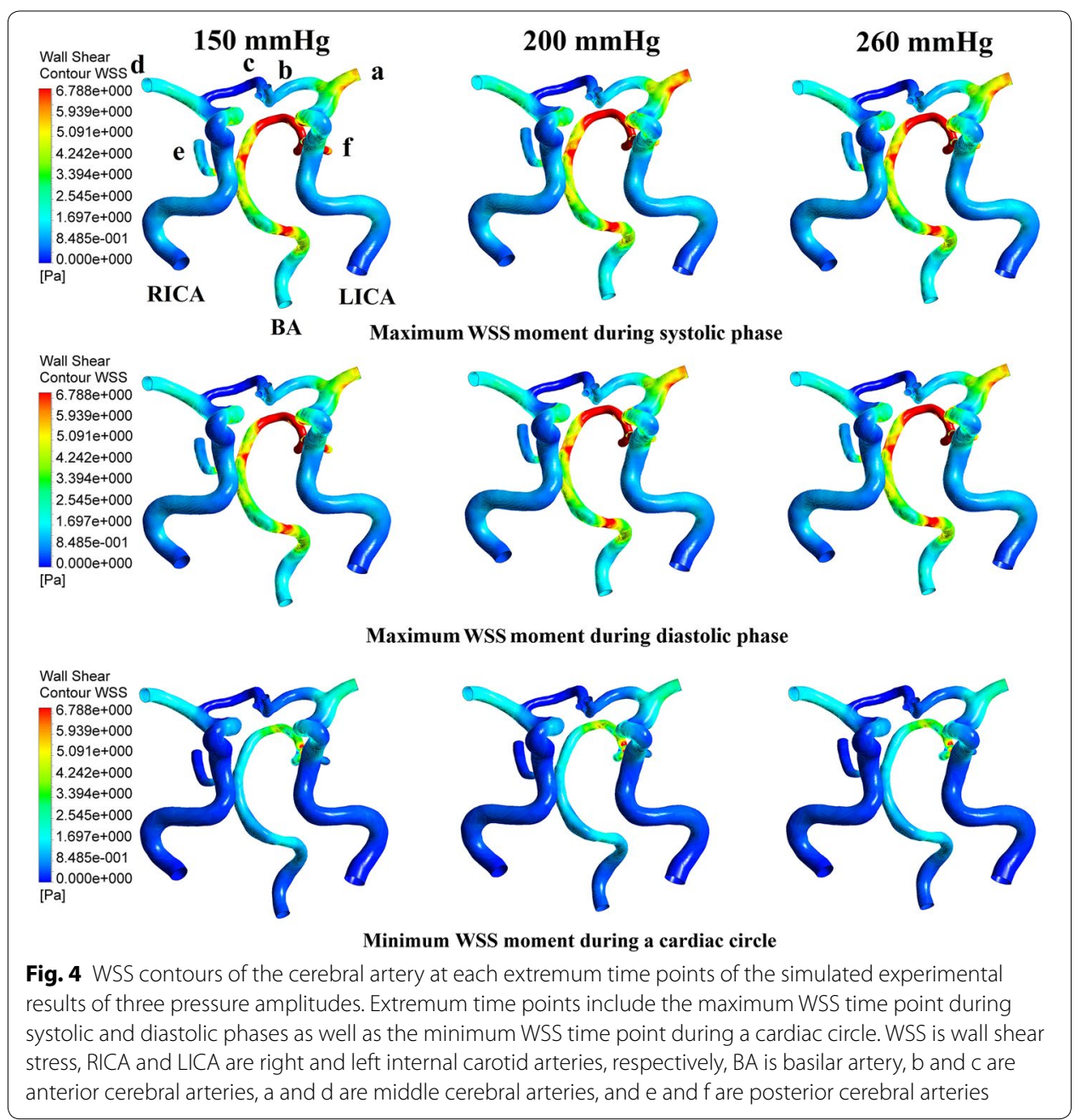



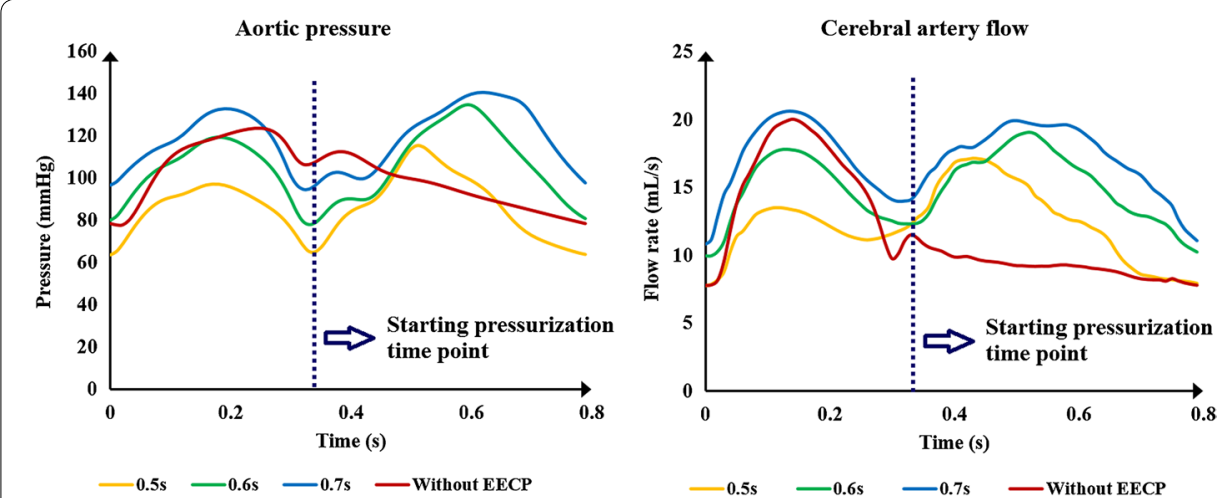

Fig. 5 Aortic pressure and CBF waveforms of simulated experimental results of three pressurization durations and waveform without EECP. Pressurization durations were determined by pressure release time points $(0.5$, 0.6 and $0.7 \mathrm{~s}$ ) and the pressure amplitudes of the three body parts were $200 \mathrm{mmHg}$. CBF is cerebral blood flow and EECP is enhanced external counterpulsation

Table 2 Mean values of MAP, CBF and time-averaged WSS (TAWSS) during a cardiac circle under three pressure release time points

\begin{tabular}{lrlr}
\hline Pressure release time point & MAP & CBF & TAWSS \\
\hline 0.5 & 86.357 & 12.239 & 1.012 \\
0.6 & 105.032 & 14.934 & 1.449 \\
0.7 & 118.221 & 17.128 & 1.869 \\
\hline
\end{tabular}

Unit: time point: $\mathrm{s}$, pressure: $\mathrm{mmHg}$, flow rate: $\mathrm{mL} / \mathrm{s}$, WSS: $\mathrm{Pa}$

MAP mean arterial pressure, CBF cerebral blood flow, WSS wall shear stress

pressure amplitude. Finally, changes were not observed when the pressure amplitude was greater than $200 \mathrm{mmHg}$.

\section{Influence of the pressurization durations of the three parts}

Pressurization duration is a parameter that influences treatment adequacy. Pressurization duration depends on pressure release time point. The simulation waveforms of aortic pressure and CBF under different pressure release time points are shown in Fig. 5. Mean values of MAP, CBF and TAWSS during a cardiac circle are displayed in Table 2, where TAWSS is the mean value of area-averaged WSS during a cardiac circle. These results show a significant improvement of hemodynamic indicators. The simulation waveforms of area-averaged WSS are shown in Fig. 6. For three pressurization durations, it could be observed that the time point of maximum WSS during systole was $0.13 \mathrm{~s}$, the time points of maximum WSS during diastole were $0.41,0.51$ and $0.49 \mathrm{~s}$, respectively, and the minimum time point during a cardiac circle was $0.0 \mathrm{~s}$. WSS contours of the cerebral artery at each extremum time point are shown in Fig. 7. Similarly, the WSS in cerebral artery increased significantly as the pressurization duration increased. The highest WSS in cerebral artery for both systole and diastole was observed for the mode of pressure release at $0.7 \mathrm{~s}$. In addition, effects of different pressurization durations on OSI are shown in Fig. 8. According to theory [27], the threshold for distinguishing high and low mean OSI is 0.02 . As a result, sizes and mean values of high OSI areas (OSI $>0.02)$, as shown in Fig. 8, were extracted. The total area size of the cerebral arteries was $5072.6 \mathrm{~mm}^{2}$, while sizes of high OSI areas under the three pressurization 


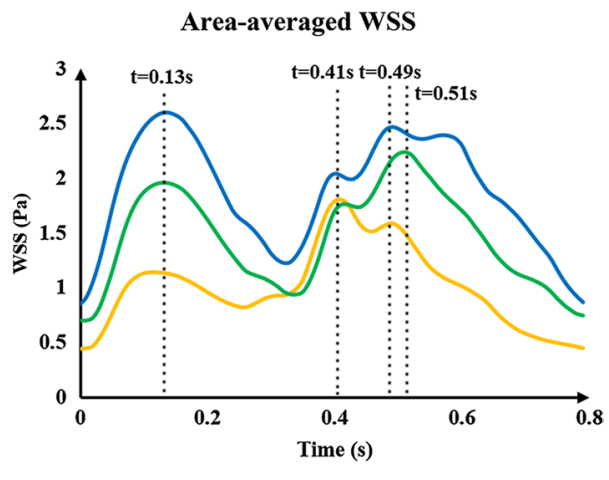

Fig. 6 Area-averaged WSS waveforms of simulated experimental results of three pressurization durations. Pressurization durations were determined by pressure release time points $(0.5,0.6$ and $0.7 \mathrm{~s})$, while pressure amplitudes of the three body parts were $200 \mathrm{mmHg}$. $0.13 \mathrm{~s}$ was the maximum time point during systolic phase under three pressure release time points, $0.41,0.51$ and $0.49 \mathrm{~s}$ were maximum time points during diastolic phase under the pressure release time points of $0.5,0.6,0.7 \mathrm{~s}$, respectively. WSS is wall shear stress

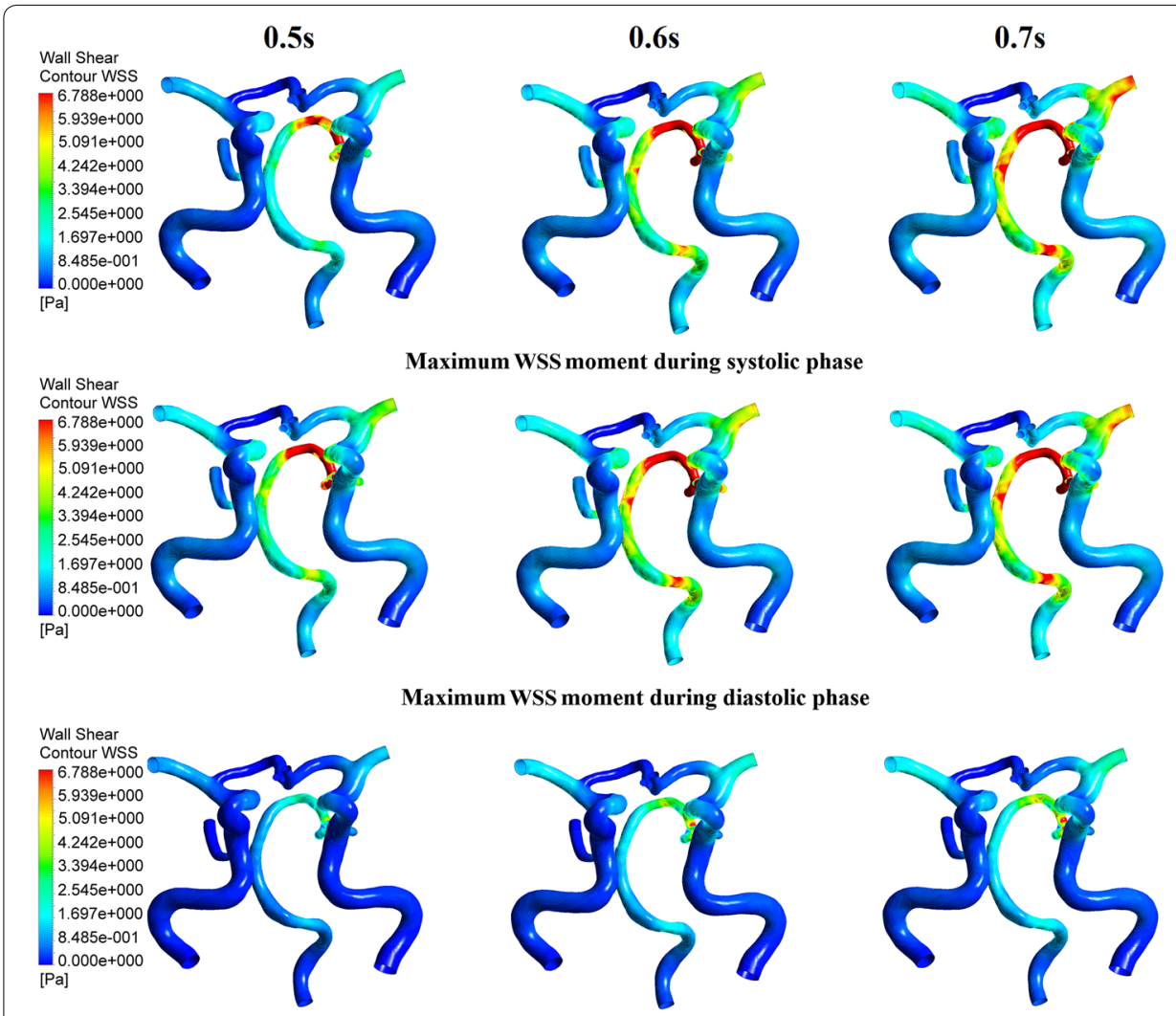

Minimum WSS moment during a cardiac circle

Fig. 7 WSS contours of cerebral artery at each extremum time points of the simulated experimental results of three pressurization durations. Extremum time points include maximum WSS time point during systolic and diastolic phases, and minimum WSS time point during a cardiac circle. WSS is wall shear stress

durations were $376.6,415.4$ and $314.8 \mathrm{~mm}^{2}$, which were $7.42 \%, 8.19 \%$ and $6.21 \%$ of the total size. The mean values of high OSI area under the three pressurization durations were 0.061 , 0.063 and 0.049 , respectively. The above data demonstrate that when pressure releases at 


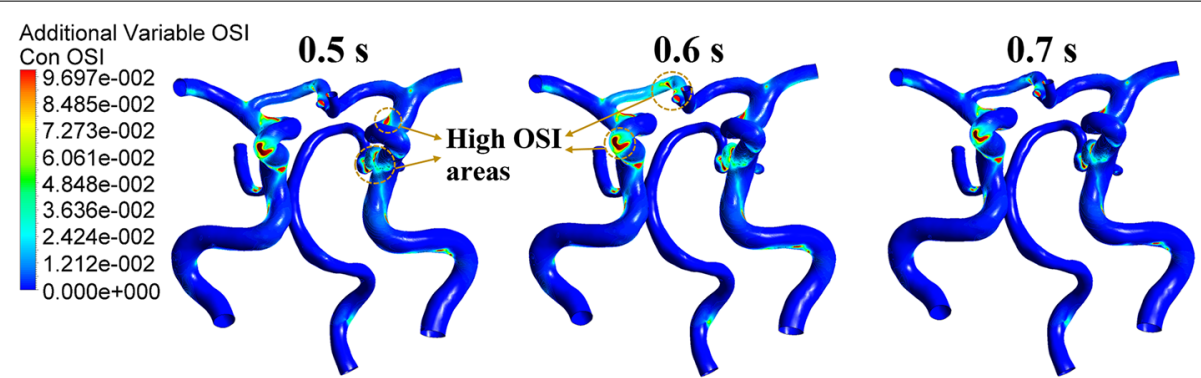

Fig. 8 OSI contours of the cerebral artery during a cardiac circle under three pressurization durations. OSI is oscillatory shear index

$0.7 \mathrm{~s}$ during a cardiac circle, both the size and mean value of high OSI area in the cerebral arteries show maximum reduction. Finally, inlet velocity and Reynolds number at the highest flow time point ( $0.13 \mathrm{~s}$ during the cardiac circle) for the mode of pressure release at $0.7 \mathrm{~s}$ were presented to examine the rationality of simulation, as the maximum flow appears at this counterpulsation mode. The velocities of three inlets were $0.65,0.74$ and $0.21 \mathrm{~m} / \mathrm{s}$, while the Reynolds numbers were $979.74,995.69$ and 219.68 , respectively. Both of these factors were in the reasonable range.

\section{Discussion}

\section{Re-thinking about hemodynamic responses to different counterpulsation modes}

When addressing the aforementioned clinical questions about the hemodynamic effects of different counterpulsation modes for patients with cerebral ischemic stroke, it can be concluded from the above results that using the same and different pressure amplitudes for each part resulted in nearly the same acute hemodynamic effects, in turn leading to the same long-term hemodynamic effects. Thus, it may not be necessary to adopt different pressure amplitudes for each body part in clinical operation of EECP. In addition, as shown in the results described in "Limitations" section, hemodynamic effects hardly changed when pressure amplitude was greater than $200 \mathrm{mmHg}$ as vascular collapse occurred in the external iliac artery, meaning that it was difficult for an even greater pressure to change the blood flow. As a result, it can be concluded that an increase in pressure amplitude may result in a slight improvement of treatment effects for stroke patients. Similar research has been conducted in clinical settings. Lin [23] used different pressure amplitudes to observe acute treatment effects for stroke patients and recorded MAP under each pressure. A comparison between our results and that clinical data is shown in Fig. 9. The relative errors of the points under each pressure were $1.47,0.95,0.13$ and $0.56 \%$, respectively. This small difference explains the accuracy of our calculations as well as the effectiveness of the model.

Differing from hemodynamic influence of pressure amplitude, the pressurization duration significantly impacted both acute hemodynamic effects and localized details. Nevertheless, as WSS and OSI have a substantial impact on benign remodeling of blood vessels during EECP, the calculation of WSS and OSI is more crucial than acute physiological indicators. According to the functional theory of VECs and 


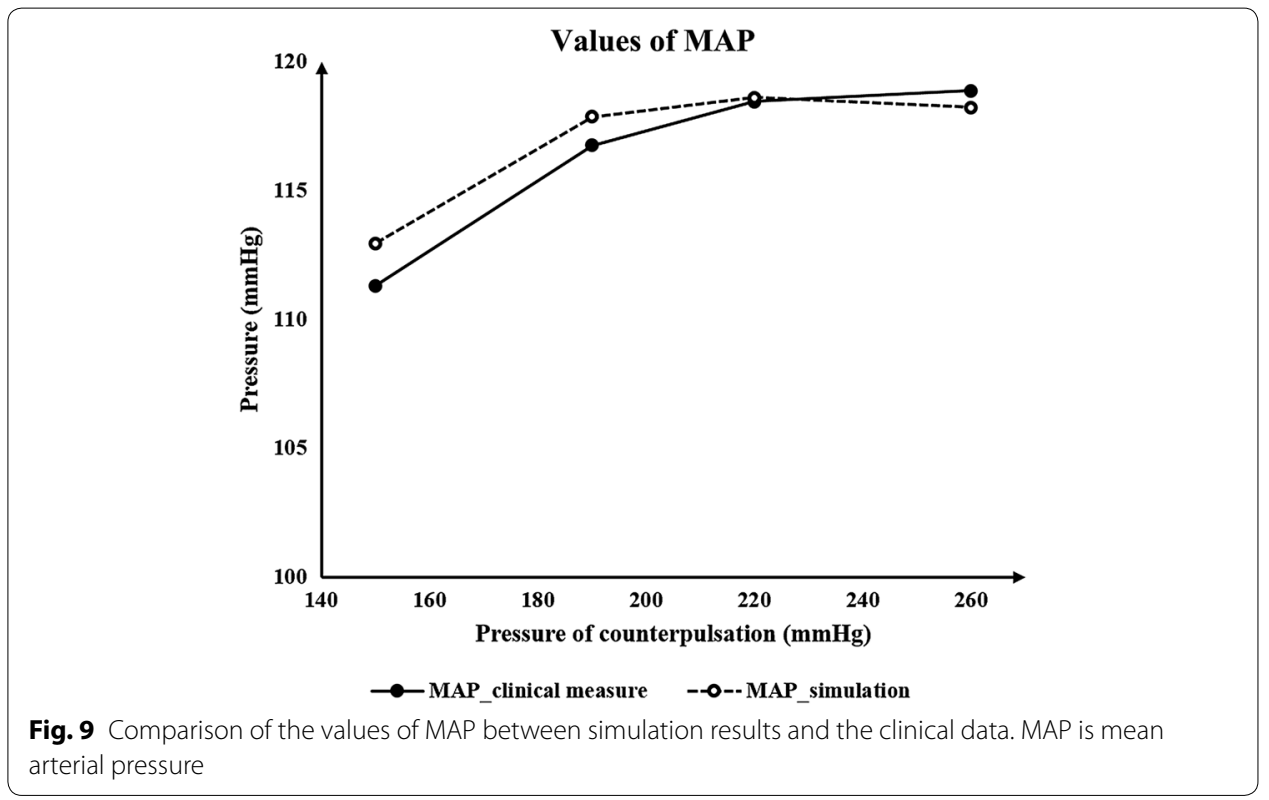

local hemodynamic WSS [12], the proper physiological range of long-term WSS for VECs is 1-7 Pa. WSS is not beneficial to atherosclerosis when it is less than $1 \mathrm{~Pa}$, and could damage VECs when greater than $7 \mathrm{~Pa}$. As can be seen in Table 2, when the pressurization duration of the counterpulsation mode was based on the 0.5-s pressure release time point, the TAWSS was $1.012 \mathrm{~Pa}$, which is very close to $1 \mathrm{~Pa}$. As a consequence, the short pressurization duration had little treatment effect for cerebral ischemic stroke if there was a stenosis. In addition, when pressurization duration was based on the 0.7-s pressure release time point, the TAWSS of $1.869 \mathrm{~Pa}$ was less than $7 \mathrm{~Pa}$, which did not damage the VECs.

Aside from WSS, blood flow characteristics are also key factors which influence the phenotype of vascular endothelial cells and promote atherosclerosis. Taylor [28] has reported that reducing flow oscillations, increasing WSS and reducing shear stress oscillations benefit atherosclerotic plaque and also that OSI is the indicator which reflects the flow characteristic of quantified oscillations in shear stress. Results in Fig. 8 and the variation of high OSI areas suggest that the maximum reduction of OSI caused by the 0.7 -s pressure release time point will benefit the vascular endothelium. This means that during the long pressurization duration, the increase in WSS and decrease in OSI are the crucial factors for inhibiting the development of atherosclerosis. In summary, pressurization duration could be lengthened to achieve possible sufficient treatment effects in clinical operation, but the pressure should not be released too late to avoid influencing normal cardiac ejection in the subsequent cardiac cycle.

Our previous study explored acute hemodynamic responses to different counterpulsation modes [29]. We found that high pressure amplitude of thighs could result in the increase in SBP and DBP, thus increasing MAP and promoting better treatment. While, in the previous study, the critical pressure value for vascular collapse was not specified, here, we presented a specified pressure value of $200.668 \mathrm{mmHg}$ for vascular collapse of external iliac artery. As a result, hemodynamic effects hardly changed when the pressure 
amplitude was greater than $200 \mathrm{mmHg}$ as vascular collapse occurred in the external iliac artery. It can be observed from Fig. 2 that when the pressure amplitude was lower than $200 \mathrm{mmHg}$, the mean arterial pressure and cerebral blood flow showed some improvement with increasing counterpulsation pressure. However, the hemodynamics showed only a small change when the pressure amplitude was over $200 \mathrm{mmHg}$, which is not specified in the previous study. Physiologically speaking, hemodynamics will not always be improved as pressure amplitude keeps increasing. Therefore, this finding is an update to those of the previous study.

\section{Limitations}

This study has some limitations. In this paper, a series of numerical simulations were conducted without verification of clinical experiments. Although the parameters in the model were adjusted according to clinical experimental results, clinical studies should be carried out to verify the quantitative conclusions. Since WSS can be calculated by flow velocity and diameter of the vessels, quantitative WSS can be measured by transcranial Doppler (TCD) [19] for verification. Beyond that, some idealized models and hypotheses were presented in the current study. The fluid simulation was based on the rigid wall assumption and Newtonian flow assumption, while the models for the calculation of critical pressure value of vascular collapse were highly idealized. Although the cerebral arteries are small, there will be a gap between assumptions and reality. In future work, the fluid-structure coupling method could be adopted to simulate a physiological situation which is closer to reality, and more indicators should be proposed to simulate the complex remodeling effects of the blood vessels as comprehensively as possible. In addition, some numerical simulation experiments could be performed to calculate a more accurate critical pressure value of vascular collapse.

In addition, only one model of cerebral artery was used in this study. In order to acquire the conclusion that is suitable for most patients, more CTA images should be collected and more models reconstructed for the hemodynamic simulation. As the physiological structure of cerebral arteries is highly similar, simulation results for most patients may not differ greatly. However, this needs to be verified by more calculation.

Results from the current study provided a general rather than individual treatment strategy for most stroke patients. This means that the same counterpulsation mode may have a different impact on the CBF of patients with different anatomical physiology structures (such as different degrees of cerebral artery stenosis). Increased CBF can increase the WSS of the entire cerebral blood vessels but improving the WSS in the infarcted territories after different degrees of stenosis in different way [30]. Beyond that, due to differences in physiological parameters such as blood pressure, patients may have differing hemodynamic responses to the same counterpulsation mode. This means that it is necessary to develop a patient-specific strategy for EECP treatment. There is a need for more clinical data to develop a patient-specific algorithm, while individual simulations could be conducted to achieve the best treatment strategy. 


\section{Conclusions}

This study established a geometric multiscale model to research the hemodynamic effects of EECP on the cerebral artery while considering vascular collapse and cerebral autoregulation. Based on this model, acute variations in blood flow, blood pressure and localized hemodynamic details of cerebral artery could be observed. We suggest that when EECP is applied to patients with cerebral ischemic stroke, it may not be necessary to adopt different pressure amplitudes for the three parts. The increasing pressure amplitude of the three body parts may improve treatment effects slightly and will not benefit patients when it is over almost $200 \mathrm{mmHg}$. During counterpulsation, pressurization duration could be increased during the cardiac circle for the possible superior treatment outcomes. A short pressurization duration $(0.5 \mathrm{~s})$ may have poor treatment effects for stroke patients.

\section{Materials and methods}

\section{Establishment of geometric multiscale model}

Establishment of the 3D model was based on computed tomography angiography (CTA) images of the cerebral artery of a volunteer. Images were provided by The Eighth Affiliated Hospital, Sun Yat-sen University. Since the aim of this study was to investigate acute and long-term hemodynamic effects of different counterpulsation modes on cerebral arteries, the method utilized should be suitable for most patients. In addition, the model of the cerebral artery should, methodologically speaking, be representative of most patients. Therefore, a natural model without stenoses was chosen for reconstruction. Cerebral arteries were reconstructed based on CTA images. The 3D geometry of cerebral arteries was generated by Mimics and smoothed by Freeform, a touch-based interactive tool for the 3D geometry editing.

Establishment of the 0D model was based on 3D reconstruction results. Lumped parameter modeling is a common method which utilizes circuit elements to simulate the blood circulatory system. The $0 \mathrm{D}$ model is often coupled to the inlet and outlet of the 3D model as a boundary condition in a geometric multiscale model. Following previous studies [31-33], we established a complete, closed-loop 0D model for the systemic simulation as shown in Fig. 10. This model had 17 artery and vein units, 8 peripheral circulation units and a cardiopulmonary circulation unit. The detailed structures of the whole blood circulatory system can be seen in Fig. 11. Existing research [33] has outlined the parameters of the $0 \mathrm{D}$ model. Based on these parameters, the value of each circuit element in our model was adjusted to match classic physiological waveforms and clinical measurements. Parameter values are shown in Tables 3 and 4.

Establishment of the geometric multiscale model of the cerebral artery was based on the $0 \mathrm{D}$ and $3 \mathrm{D}$ models. Based on the physiological structure of the 3D model of the cerebral artery, the coupling interface of the geometric multiscale model was designed to align with the internal carotid artery, basilar artery and brain microcirculation [34]. Utilizing a coupling algorithm [35], the geometric multiscale model of the cerebral artery was developed, as shown in Fig. 10. In the coupling algorithm, the 0D model calculates the inlet flow and outlet pressure as the boundary conditions for the 3D model calculation, while the inlet pressure and outlet flow calculated by the 3D model are provided for missing values in the OD model calculation. The data interaction between the $0 \mathrm{D}$ model and 3D model follows these formulas: 


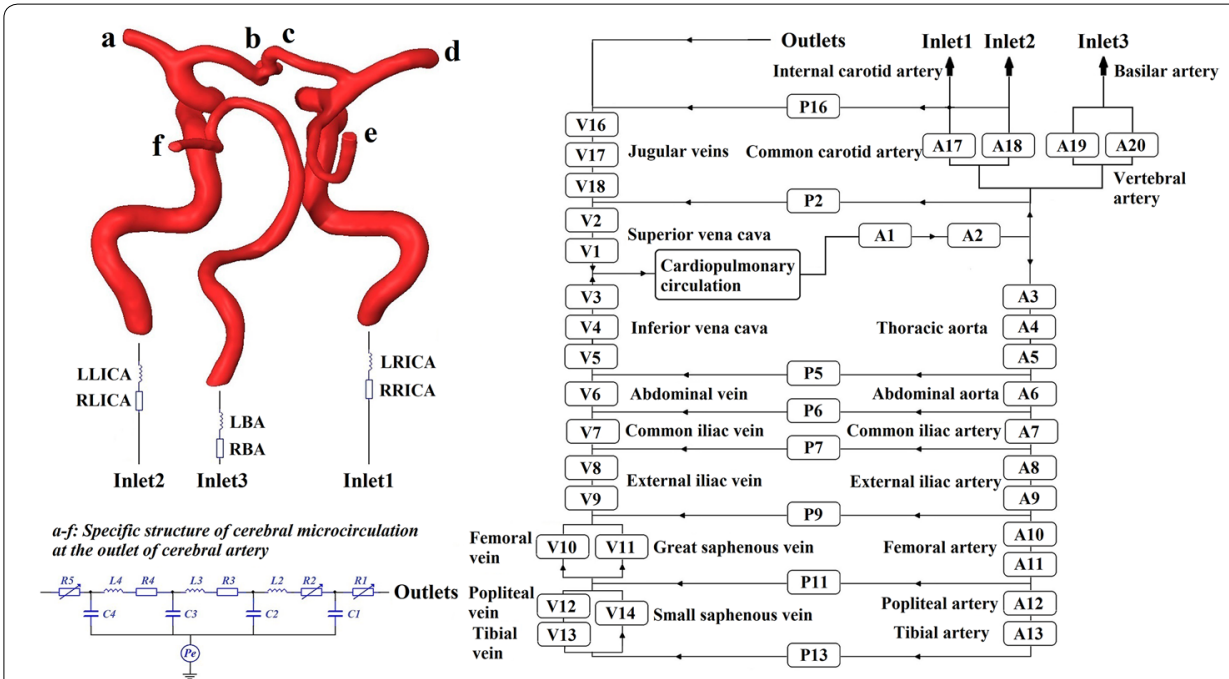

Fig. 10 Geometric multiscale model of the cerebral artery with three inlets and six outlets. At the inlet of the 3D model, the OD model of right and left internal carotid arteries (RICA, LICA) and the basilar artery (BA) were coupled; at the outlet of the 3D model, anterior cerebral arteries $(b, c)$, middle cerebral arteries $(a, d)$ and posterior cerebral arteries $(e, f)$ were coupled

\section{Lumped parameter model of cardiopulmonary circulation

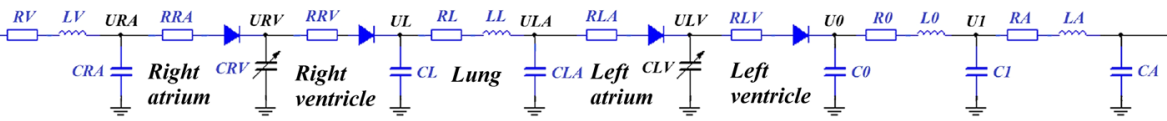 \\ A: Lumped parameter model of arterial unit

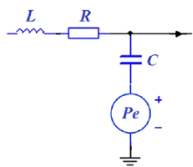 \\ $V:$ Lumped parameter model of venous unit

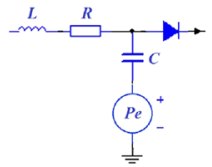 \\ P. Lumped parameter model of peripheral circulation}

Fig. 11 Detailed structures of the whole blood circulatory system. The voltage sources Pe in artery and vein units were used to simulate the pressure provided by the counterpulsation cuffs, which only exist in A8-A13 and V8-V13. Diodes in V8-V13 were used to simulate the lower limbs'venous valve

$$
\begin{aligned}
\bar{P}_{3 \mathrm{D}, \text { in }} & =\frac{1}{A_{3 \mathrm{D}, \text { in }}} \int_{\tau_{\text {in }}} P \mathrm{~d} \tau=P_{0 \mathrm{D}, \text { in }} \\
Q_{3 \mathrm{D}, \text { out }} & =\rho \int_{\tau_{\text {out }}} \mu n_{i} \mathrm{~d} \tau=Q_{0 \mathrm{D}, \text { out }}
\end{aligned}
$$

where $\bar{P}_{3 \mathrm{D} \text {,in }}$ is the mean inlet pressure calculated by the $3 \mathrm{D}$ model, $A_{3 \mathrm{D} \text {,in }}$ is the inlet area of the 3D model, $\tau_{\text {in }}$ is integral domain (the inlet plane of the $3 \mathrm{D}$ model), $P$ is the pressure of each element on the inlet plane of the $3 \mathrm{D}$ model, $\mathrm{d} \tau$ is the differential area element, $P_{0 \mathrm{D} \text {,in }}$ is the missing value of the $0 \mathrm{D}$ model, which is the mean inlet pressure of the 3D model, $Q_{3 \mathrm{D}, \text { out }}$ is the outlet flow calculated by the 3D model, $\rho$ is blood density, $\tau_{\text {out }}$ is integral domain (the outlet plane of the $3 \mathrm{D}$ model), $\mu$ is the node velocity of the outlet plane of the 3D model, $n_{i}$ is the normal vector of the outlet plane and $Q_{0 D \text {,out }}$ is the missing value of the $0 \mathrm{D}$ model (the outlet flow of the $3 \mathrm{D}$ model). The inlet of the 3D 
Table 3 Parameters of the blood circulatory system

\begin{tabular}{|c|c|c|c|c|c|c|c|c|c|}
\hline \multirow[t]{2}{*}{ Serial number } & \multicolumn{3}{|c|}{ Arterial unit } & \multicolumn{3}{|c|}{ Venous unit } & \multicolumn{3}{|c|}{ Peripheral circulation } \\
\hline & $R$ & $C$ & $L$ & $R$ & $C$ & $L$ & $\mathrm{Ra}$ & $\mathbf{R v}$ & $C$ \\
\hline 1 & 0.00426 & 0.1050 & 0.00035 & 0.03780 & 0.0800 & 0.00050 & & & \\
\hline 2 & 0.00395 & 0.1050 & 0.00020 & 0.03860 & 0.0950 & 0.00051 & 1.50 & 2.60 & 0.00105 \\
\hline 3 & 0.00405 & 0.1067 & 0.00012 & 0.05490 & 0.0200 & 0.00008 & & & \\
\hline 4 & 0.00695 & 0.1041 & 0.00010 & 0.05560 & 0.0200 & 0.00008 & & & \\
\hline 5 & 0.00897 & 0.0350 & 0.00010 & 0.06030 & 0.0280 & 0.00010 & 2.36 & 2.34 & 0.00520 \\
\hline 6 & 0.00933 & 0.0240 & 0.00023 & 0.08080 & 0.0101 & 0.00018 & 3.33 & 2.96 & 0.00103 \\
\hline 7 & 0.00848 & 0.0168 & 0.00022 & 0.12000 & 0.0100 & 0.00014 & 4.18 & 3.55 & 0.00108 \\
\hline 8 & 0.01000 & 0.3050 & 0.02275 & 0.20000 & 0.0900 & 0.00521 & & & \\
\hline 9 & 0.01200 & 0.0150 & 0.02275 & 0.19000 & 0.0300 & 0.01187 & 5.30 & 4.20 & 0.00100 \\
\hline 10 & 0.12800 & 0.3620 & 0.03528 & 0.51000 & 0.0400 & 0.01581 & & & \\
\hline 11 & 0.15800 & 0.0520 & 0.03500 & 0.53000 & 0.0500 & 0.01855 & 5.40 & 4.70 & 0.00100 \\
\hline 12 & 0.17500 & 0.0520 & 0.00514 & 1.42000 & 0.0200 & 0.03135 & & & \\
\hline 13 & 0.19100 & 0.0510 & 0.00514 & 1.41000 & 0.0100 & 0.04089 & 6.05 & 5.35 & 0.00010 \\
\hline 14 & & & & 1.41000 & 0.0100 & 0.04089 & & & \\
\hline 16 & & & & 0.18000 & 0.0600 & 0.00040 & 4.40 & 4.70 & 0.00168 \\
\hline 17 & 0.02535 & 0.0150 & 0.00015 & 0.18000 & 0.0700 & 0.00035 & & & \\
\hline 18 & 0.02518 & 0.0150 & 0.00015 & 0.16000 & 0.0070 & 0.00030 & & & \\
\hline 19 & 0.02535 & 0.0100 & 0.00020 & & & & & & \\
\hline 20 & 0.02518 & 0.0100 & 0.00020 & & & & & & \\
\hline
\end{tabular}

Unit: $R: \mathrm{mmHg} \mathrm{s} / \mathrm{mL}, \mathrm{C}: \mathrm{mL} / \mathrm{mmHg}, \mathrm{L}: \mathrm{mmHg} \mathrm{s}{ }^{2} / \mathrm{mL}$

$R$ : resistance, $C$ : capacitance, $L$ : inductance, Ra: arterial microcirculatory resistance, $R v$ : venous microcirculatory resistance

Table 4 Parameters of cardiopulmonary circulation and inlet of 3D model

\begin{tabular}{llllll}
\hline $\boldsymbol{R}$ & \multicolumn{5}{l}{$\boldsymbol{L}$} \\
\hline RV & 0.10271 & CRA & 0.5946 & LV & 0.00012 \\
RRA & 0.00353 & CL & 0.3436 & LL & 0.00021 \\
RRV & 0.00023 & CLA & 2.5000 & L0 & 0.00150 \\
RL & 0.00688 & C0 & 0.1500 & LA & 0.00070 \\
RLA & 0.00701 & C1 & 0.1950 & LLICA & 0.15000 \\
RLV & 0.50300 & CA & 0.1800 & LRICA & 0.15000 \\
R0 & 0.03771 & & & LBA & 1.12000 \\
RA & 0.00251 & & & & \\
RLICA & 0.05030 & & & & \\
RRICA & 0.05010 & & & & \\
RBA & 0.04030 & & & &
\end{tabular}

Unit: $R: \mathrm{mmHg} \mathrm{s} / \mathrm{mL}, \mathrm{C}: \mathrm{mL} / \mathrm{mmHg}, \mathrm{L}: \mathrm{mmHg} \mathrm{s}{ }^{2} / \mathrm{mL}$

model was coupled to the internal carotid artery and basilar artery, while the outlet of the 3D model ( $\mathrm{a}-\mathrm{f})$ was coupled to the cerebral microcirculation. Specific structures and parameters of the cerebral microcirculation at the outlet of the cerebral artery have previously been described [34].

\section{Hemodynamic calculation details of the geometric multiscale model}

Hemodynamic calculation of the 3D model was conducted with fluid simulation software ANSYS-CFX. Fluid density was $1050 \mathrm{~kg} / \mathrm{m}^{3}$, viscosity was $0.0035 \mathrm{~Pa} / \mathrm{s}$, the number 
of fluid elements was $1,186,933$, the vessel wall was simplified to a rigid wall and blood flow was transient. In addition, local blood flow was considered to be performed at a constant temperature, ignoring the change in heat, while the energy conservation equation was disregarded. Therefore, pulsating blood flow in the cerebral artery is a transient incompressible Newtonian fluid flow problem.

The Navier-Stokes equations were applied for hemodynamic simulations of the 3D model, and the flow was assumed to be laminar. Discretization in time was based on second-order backward Euler and an implicit scheme. During multiscale calculation, the time step of 3D model was $0.001 \mathrm{~s}$, while the time step of 0D model was $0.00001 \mathrm{~s}$. The two models achieved a data exchange after 100 times calculation of OD model. The continuous computational domain was divided into finite discrete sets, which were mesh nodes, while discretization in space was based on divided mesh nodes. The differential equations and their solutions on these mesh nodes were transformed into corresponding algebraic equations, meaning that discrete equations were established. Discrete equations were solved, and the solution on each node could be acquired. In addition, approximate solutions between nodes were considered to be a smooth variation, while an interpolation method was used to obtain approximate solutions for the entire computational domain.

The heart module is a key source of power for the entire circulatory system. Ventricular systolic and diastolic function can be reflected by the pressure-volume relationship of ventricles. With the same ventricular volume variation, greater ventricular contraction pressure indicates a stronger systolic heart function. A time-varying function $E(t)$ that can reflect both the systolic and the diastolic functions of the ventricle was used in the heart module to simulate ventricular contraction. The function $E(t)$ can be described by the ventricular pressure-volume relationship, as follows [36]:

$$
E(t)=\frac{P_{\mathrm{sv}}(t)}{V_{\mathrm{sv}}(t)-V_{0}}
$$

where $P_{\mathrm{sv}}(t)$ is the time function of ventricular pressure $(\mathrm{mmHg}), V_{\mathrm{sv}}(t)$ is the time function of ventricular volume $(\mathrm{mL})$ and $V_{0}$ is the ventricular reference volume $(\mathrm{mL})$, a theoretical volume relative to "zero ventricular pressure." Application of ventricular contraction function $E(t)$ to the variable capacitances of both left $(C L V(t))$ and right ventricles $(C R V(t))$, as shown in Fig. 11, produced a pulse wave on $C 0$ which acted as an energy source. Mathematically, one could fit Eq. (4) using the following approximation to describe the ventricular systole function:

$$
E(t)=\left(E_{\max }-E_{\min }\right) \cdot E_{n}\left(t_{n}\right)+E_{\min }
$$

where $E_{n}\left(t_{n}\right)$ is a double hill function, as follows [37]:

$$
E_{n}\left(t_{n}\right)=1.55\left[\frac{\left(\frac{t_{n}}{0.7}\right)^{1.9}}{1+\left(\frac{t_{n}}{0.7}\right)^{1.9}}\right]\left[\frac{1}{1+\left(\frac{t_{n}}{1.17}\right)^{21.9}}\right]
$$

where $t_{n}$ is $t / T_{\max }$, and $T_{\max }$ has a linear relationship with the personalized cardiac cycle $t_{\mathrm{c}}(0.8 \mathrm{~s})$ as follows:

$$
T_{\max }=0.2+0.15 t_{\mathrm{c}}
$$



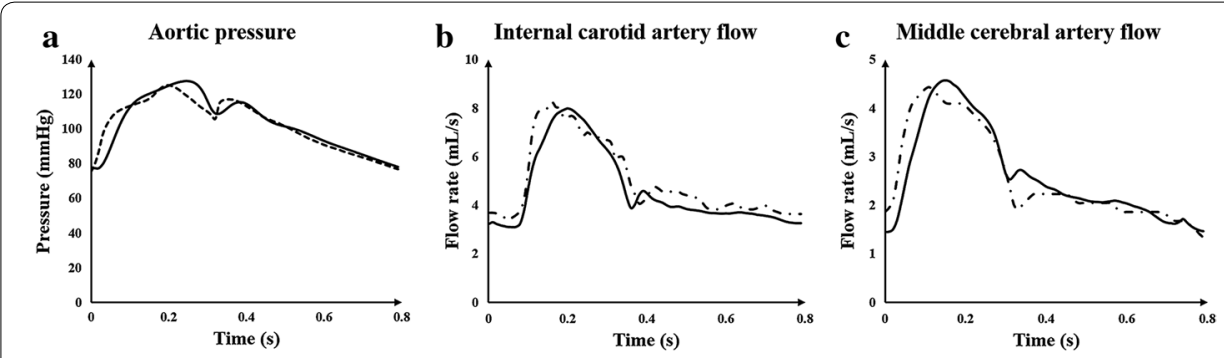

----Classical physiological waveforms - - - Clinical measurement waveforms -Waveforms calculated by our model

Fig. 12 Effectiveness validation of the model without applying counterpulsation. a Comparison of aortic pressure between the classical physiological and simulated waveforms calculated by our model, while (b) and $(\mathbf{c})$ are the comparison of internal carotid artery flow and middle cerebral artery flow between the clinical measurement and simulated waveforms

Table 5 Steady-state analysis of mesh dependency for 3D model of cerebral artery by aiming at WSS and CBF with constant pressure boundary conditions

\begin{tabular}{|c|c|c|c|c|c|c|c|}
\hline \multicolumn{2}{|l|}{ Size } & \multicolumn{2}{|c|}{ Boundary conditions } & \multirow[t]{2}{*}{ CBF } & \multirow{2}{*}{$\begin{array}{l}\text { Differences } \\
\text { percentage }\end{array}$} & \multirow{2}{*}{$\begin{array}{l}\text { Area- } \\
\text { averaged } \\
\text { WSS }\end{array}$} & \multirow{2}{*}{$\begin{array}{l}\text { Differences } \\
\text { percentage }\end{array}$} \\
\hline Nodes & Elements & Inlet pressure & Outlet pressure & & & & \\
\hline 316,652 & 394,380 & 90.2 & 85.2 & 18.053 & & 1.699 & \\
\hline 590,411 & 798,195 & 90.2 & 85.2 & 17.425 & 0.0348 & 1.608 & 0.0536 \\
\hline 919,703 & $1,186,933$ & 90.2 & 85.2 & 17.290 & 0.0077 & 1.596 & 0.0075 \\
\hline
\end{tabular}

Pressure unit: $\mathrm{mmHg}$, flow rate unit: $\mathrm{mL} / \mathrm{s}$, WSS unit: $\mathrm{Pa}$

CBF cerebral blood flow, WSS wall shear stress

Values of $E_{\max }$ and $E_{\min }$ significantly impact the aortic pressure and cardiac output. $E_{\max }$ and $E_{\min }$ values for left and right ventricles were determined differently due to their different systolic strengths. Combined with the physiological data of most patients, it was determined that $E_{\text {max_left }}$ was $6.0, E_{\text {min_left }}$ was $0.012, E_{\text {max_right }}$ was 0.00042 , and $E_{\text {min_right }}$ was 0.00003 . Using the above methods and parameters, physiological waveforms were calculated. Comparisons between classical physiological waveforms, clinical measurement waveforms and waveforms calculated by our model are shown in Fig. 12. According to clinical reports, the total CBF is approximately $15-20 \%$ of cardiac output [38]. The CBF is fed by both internal carotid arteries and vertebral arteries, while the flow rate of internal carotid arteries tends to be three times the vertebral artery flow [39]. In our model, the calculated internal carotid artery flow is $9.1 \mathrm{~mL} / \mathrm{s}$, the vertebral artery flow is $3 \mathrm{~mL} / \mathrm{s}$, and the total CBF is $12.1 \mathrm{~mL} / \mathrm{s}, 15.3 \%$ of cardiac output. This small difference in numerical values and waveforms between classical and simulation results supports the practicability of our model.

Since the multiscale model in this study was a closed-loop, huge and complex model coupling by cerebral artery and blood circulatory system, the calculation cannot be convergent through the use of rough mesh or bigger time step. The time step of the 3D and OD models was optimized to decrease the calculation time, while attaining convergence. As a result, a steady-state analysis of mesh dependency by aiming at WSS and CBF with constant pressure boundary conditions was conducted, as shown in Table 5. The time step tests aiming at aortic pressure can be seen in Fig. 13. Test results ensured that the 

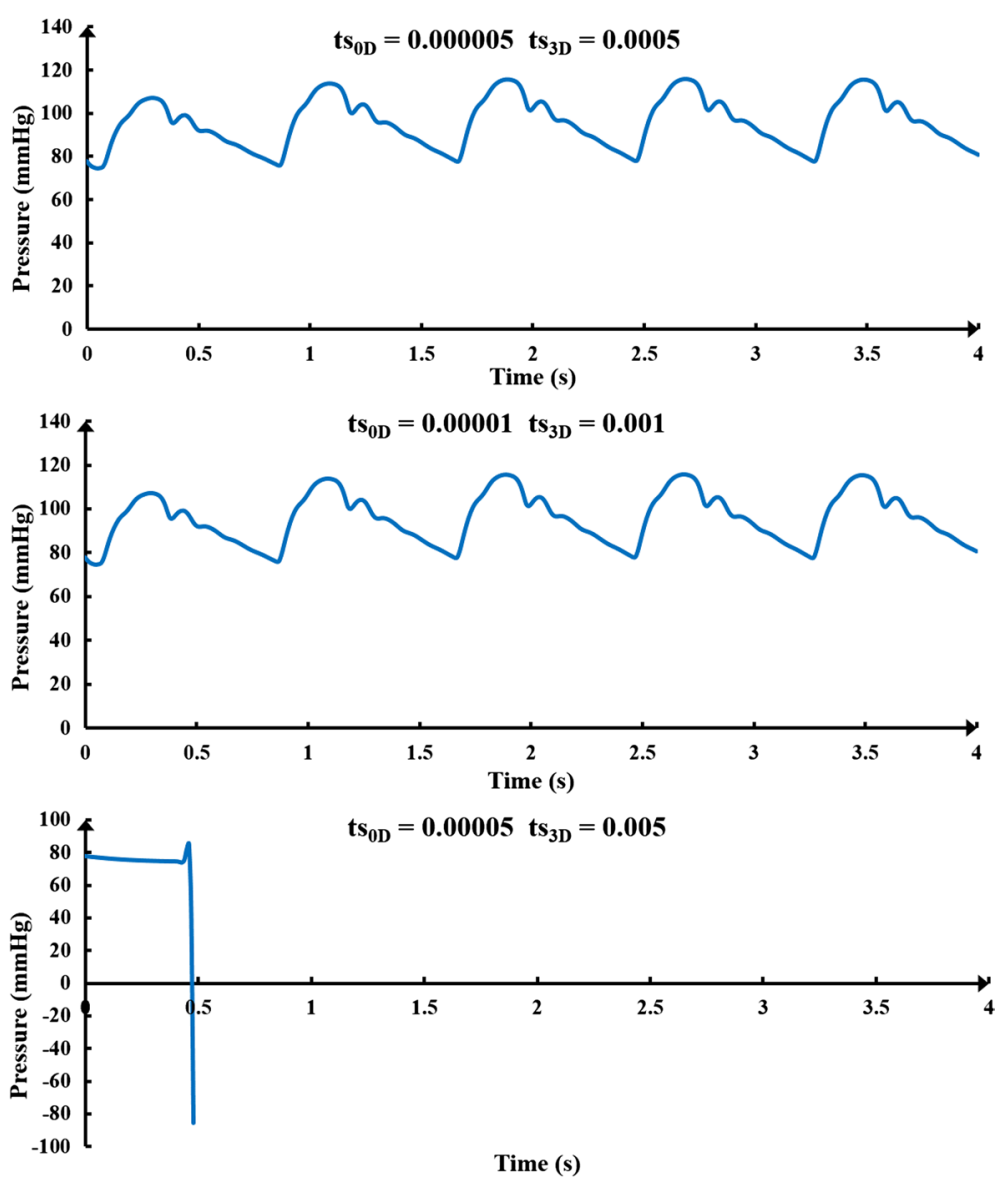

Fig. 13 Time step test results. The $t s_{O D}$ is the time step of $0 D$ model (lumped parameter model) and the $t s_{3 D}$ is the time step of 3D model

mesh size $\left(1,186,933\right.$ fluid elements) and time step chosen in this study $\left(\mathrm{ts}_{0 \mathrm{D}}\right.$ was 0.00001 and $\mathrm{ts}_{3 \mathrm{D}}$ was 0.001 ) were optimal and that calculation results were credible.

\section{Application of EECP}

Application of pressure was based on four different parameters: inflation and deflation times, inflation time point, pressurization duration and pressure amplitude. When combined with the clinical operation, inflation and deflation times were set as $5 \mathrm{~ms}$, following a previous study [31]. The inflation time point means the start pressurization time point of counterpulsation cuffs during the cardiac cycle. Based on the clinical operation, the inflation time point of the cuffs of the EECP equipment was triggered by the R-wave of electrocardiogram, which was the starting point of systole during a cardiac circle. After a systolic delay, which is approximately $0.25 \mathrm{~s}$, cuffs were sequentially inflated. As a result, the inflation time point for calves in this study was set as $0.25 \mathrm{~s}$ during a cardiac circle. Based on clinical experience, EECP should be applied in a sequential manner and the interval between each part should be $0.05 \mathrm{~s}$ [40]. Therefore, inflation time points for calves, thighs and buttocks were $0.25,0.30$ and $0.35 \mathrm{~s}$, respectively. Differing from the inflation time point as well as inflation and deflation times, selections of the 
pressurization duration and pressure amplitude should be carefully considered as they determine the different treatment effects of counterpulsation modes. Following inflation time points, inflation and deflation times were determined, and hemodynamic indicators, including MAP, CBF and WSS, were calculated under different pressure amplitudes and pressurization durations for each of the body parts to investigate the hemodynamic effects of different counterpulsation modes, where pressure amplitude was in the clinical range [41]. Our previous study has presented the control chart of the counterpulsation mode [29]. In this study, in order to examine both acute and long-term hemodynamic effects, a series of numerical simulations were conducted to answer the clinical queries about optimal counterpulsation strategies.

In order to determine whether similar or different pressure amplitudes at the calves, thighs and buttocks should be maintained, comparison experiments were carried out with the 0.65-s pressure release time points during a cardiac circle of the three body parts. Five groups with unequal pressure differences between each part were the experimental group, and a group without application of EECP was the control group. According to the general pressure application method, the order of pressure amplitudes of the three parts tends to be that calf pressure is greater than or equal to thigh pressure, while thigh pressure is greater than or equal to buttock pressure [42]

To determine optimal pressure amplitudes and pressurization durations, different counterpulsation modes were applied to investigate hemodynamic responses. In the clinical operation, cuffs wrapped around the three parts usually release at the same time point. As a result, once inflation time points were determined, pressurization duration depended on the pressure release time point of the three body parts. Based on the 0.7-s pressure release time points during a cardiac circle of those parts, a series of pressure amplitudes $(150-260 \mathrm{mmHg})$ was applied to observe hemodynamic variations of the cerebral artery. In addition, with the $200-\mathrm{mmHg}$ pressure amplitude of each part, three pressure release time points $(0.5,0.6$ and $0.7 \mathrm{~s})$ during a cardiac circle were applied to explore the hemodynamic influence of pressurization duration. Hemodynamic indicators, including MAP, CBF, and WSS, were compared to evaluate treatment effects. It should also be noted that for a cardiac circle of $0.8 \mathrm{~s}$, the pressure release time point was not more than $0.7 \mathrm{~s}$ to avoid the danger of influencing the normal cardiac ejection in the subsequent cardiac cycle. This is because when the pressure is released, it takes some time for the blood to perfuse into the lower body.

\section{Vascular collapse during counterpulsation}

Vascular collapse is a classic vessel instability issue under external pressure. During EECP, arteries in the lower body are compressed by the cuffs. If the pressure amplitude is greater than a critical value, vascular collapse occurs, and the arteries will close. However, the critical value for vascular collapse of each artery in the lower body has yet not been determined. The critical pressure value of vascular collapse is the sum of pressure inside the blood vessel and the external pressure required for vascular instability. To achieve calculation of the threshold value, the vessel type must first be determined. By assuming that a blood vessel is a standard cylindrical vessel, different parts of the arteries in the lower body were characterized as either long cylindrical vessels or short cylindrical vessels, according to length, thickness and internal diameter. When the length of a vessel exceeded a critical value, that 
vessel was considered a long cylindrical vessel. Otherwise, it was considered a short cylindrical vessel. The formula for calculating the critical length is [43]:

$$
L_{\mathrm{cr}}=1.17 D \sqrt{\frac{D}{\delta_{e}}}
$$

where $D$ is the internal diameter of the vessel and $\delta_{e}$ is the vessel's thickness. For short cylindrical blood vessels, the Pamm formula, commonly used in engineering, was utilized to calculate the critical value of the external pressure for vascular instability. This formula is as follows [43]:

$$
P_{\mathrm{cr}}=\frac{2.59 E \delta_{e}^{2}}{L D \sqrt{\frac{D}{\delta_{e}}}}
$$

where $E$ is the Young's modulus and $L$ is the vessel's length. For long cylindrical blood vessels, the formula of critical pressure for vascular instability is as follows [43]:

$$
P_{\mathrm{cr}}=\frac{2 E}{1-\mu^{2}}\left(\frac{\delta_{e}}{D}\right)^{3}
$$

where $\mu$ is Poisson's ratio. Based on physiological parameters of the external iliac artery, femoral artery, popliteal artery and tibial artery in the lower body, as shown in Table 6, the critical pressure for vascular instability of each part can be calculated [44-46].

The above calculation method of critical pressure for vascular instability was only for blood vessels without internal blood pressure. However, in actual human blood vessels, a pulsating blood pressure changes with time. When counterpulsation is applied, the pressure value required for vascular collapse should be the sum of the critical pressure for vascular instability and internal blood pressure at the current time point. Inflation time points for the cuffs wrapped around calves, thighs and buttocks were $0.25,0.30$ and $0.35 \mathrm{~s}$, respectively, while the blood pressure for each part was 77.61, 78.32 and $108.38 \mathrm{mmHg}$, respectively. This means that the external pressure values required for collapse of the external iliac artery, femoral artery, popliteal artery and tibial artery were 200.668, 358.017, 246.765 and $87.194 \mathrm{mmHg}$, respectively. Due to differences in the personal physiological structure and

Table 6 Parameters and critical pressures for vascular instability of lower body arteries

\begin{tabular}{lllll}
\hline Parameter & External iliac artery & Femoral artery & Popliteal artery & Tibial artery \\
\hline Internal diameter & 8.900 & 5.000 & 4.730 & 2.500 \\
Thickness & 1.230 & 1.000 & 0.800 & 0.500 \\
Length & 103.410 & 297.290 & 167.340 & 158.670 \\
Young's modulus & 1.750 & 1.750 & 1.750 & 1.750 \\
Poisson's ratio & 0.499 & 0.499 & 0.499 & 0.499 \\
Critical length & 28.010 & 13.081 & 13.457 & 6.540 \\
Container type & Long cylinder & Long cylinder & Long cylinder & Short cylinder \\
Critical pressure for & 92.288 & 279.697 & 169.155 & 9.584 \\
vascular instability & & & & \\
\hline
\end{tabular}

Unit: internal diameter, thickness, length and critical length: $\mathrm{mm}$, Young's modulus: MPa, pressure: $\mathrm{mmHg}$ 
indicators, these results may not be suitable for each patient. However, they could be used as a reference for the critical external pressure value of lower body vascular collapse for the majority of patients.

\section{Simulation of cerebral autoregulation}

Cerebral autoregulation is an adaptive regulation function of cerebral blood vessels for blood pressure variation $[5,47,48]$. Due to the existence of cerebral autoregulation, there is no significant variation in CBF for healthy people when blood pressure is increased. However, in stroke patients, cerebral autoregulation is weaker than it is in healthy bodies. When counterpulsation is applied, the increased blood pressure will significantly increase the $\mathrm{CBF}$ during the diastole, effectively improving the cerebral ischemia condition. This is the treatment mechanism of EECP for stroke patients. The CBF formula is as follows:

$$
\mathrm{CBF}=\mathrm{CPP} / \mathrm{CVR}
$$

where CPP is cerebral perfusion pressure, and CVR is cerebral vascular resistance. The formula for CPP can be seen below:

$$
\mathrm{CPP}=\mathrm{MAP}-\mathrm{ICP}
$$

where MAP is mean arterial pressure, and ICP is intracranial pressure. The relationships between CBF, MAP and CVR can be deduced using the following formula:

$$
\mathrm{CBF}=(\mathrm{MAP}-\mathrm{ICP}) / \mathrm{CVR}
$$

When blood pressure changes, the variation of ICP is not appreciable [49]; therefore, the variation of CPP depends on MAP. This means that the change in CVR is the main cause of cerebral autoregulation which maintains the stability of CBF during blood pressure changes. The authors of one clinical experiment found that cerebrovascular blood vessel lumen diameter variations correspond to blood pressure regulation [50]. When MAP increased by $30 \mathrm{mmHg}$, the average lumen diameter of the carotid artery, the proximal middle cerebral artery as well as the vertebral artery all decreased by approximately $4 \%$, while the lumen diameter of the anterior cerebral artery and the distal middle cerebral artery decreased by $29 \%$ and $21 \%$, respectively [50]. This means that, during EECP, an increase in MAP leads to an increase in CPP and varying degrees of adaptive contraction in cerebral arteries, thus increasing vascular resistance and maintaining $\mathrm{CBF}$ stability. The anterior cerebral and distal middle cerebral arteries contract much more than the vertebral and basilar arteries. Consequently, in the model, the resistances of the anterior cerebral $\left(R 1 \_c\right.$ and $\left.R 1 \_b\right)$ and distal middle cerebral arteries $\left(R 2 \_d\right.$ and $\left.R 2 \_a\right)$ increased significantly, while resistances of the internal carotid ( $R A 17$ and $R A 18$ ), proximal middle cerebral ( $R 1_{-} d$ and $\left.R 1 \_a\right)$, vertebral $(R A 19$ and $R A 20)$ and posterior cerebral arteries (R1_e and $\left.R 1 \_f\right)$ only showed a slight increase.

This qualitatively demonstrates that the resistance of each cerebral artery branch increases with the pulsation variation of blood pressure during counterpulsation. The quantitative variation in the resistance of each branch needs to be provided in the model. According to a typical diagram of the relationship between CPP and CBF [51], as shown in Fig. 14, when CPP was greater than $55 \mathrm{mmHg}$ and less than $95 \mathrm{mmHg}$, CBF remained stable. It can therefore be assumed that cerebral vascular resistance increased linearly with increasing CPP within this range. When CPP was greater than $95 \mathrm{mmHg}$, CBF 


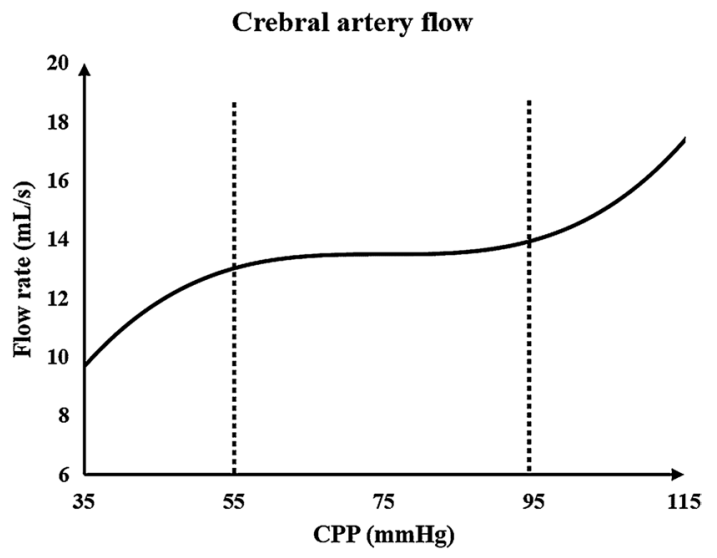

Fig. 14 Typical diagram of the relationship between CPP and CBF. CPP is the cerebral perfusion pressure and $\mathrm{CBF}$ is cerebral blood flow

demonstrated a strong increasing trend, indicating that cerebral vascular resistance was stable at the threshold with a slight increase. According to this hypothesis, the equation for cerebral vascular resistance variation with CPP during counterpulsation is as follows:

$$
R=\left\{\begin{array}{cc}
k *(\mathrm{CPP}-55), & 55 \leq \mathrm{CPP} \leq 95 \\
k * 40, & \mathrm{CPP}>95
\end{array}\right.
$$

where $R$ is the variable resistance of each cerebral vascular branch and the coefficient $k$ reflects the ability of cerebral autoregulation. Considering that the regulation abilities of patients with cerebral ischemic stroke are weaker than that of healthy individuals [47], $k$ was set to 0.5 in the current study. By adjusting the variable resistance of each branch in the cerebral vascular microcirculatory structure in Fig. 10, variations of the cerebral vascular resistance along with blood pressure during counterpulsation could be simulated. The ICP waveform [52] was applied to voltage source Pe of the cerebral vascular microcirculation as shown in Fig. 10 and was used to simulate the intracranial pressure. By simulating the autoregulation mechanism, calculated waveforms before and during EECP were compared with clinical waveforms from our previous study [29]. The small difference confirmed the effectiveness of this method.

\section{Abbreviations}

EECP: enhanced external counterpulsation; OD: zero-dimensional; 3D: three-dimensional; MAP: mean arterial pressure; CBF: cerebral blood flow; WSS: wall shear stress; FDA: Food and Drug Administration; SBP: systolic blood pressure; DBP: diastolic blood pressure; VECs: vascular endothelial cells; OSI: oscillatory shear index; WSSG: wall shear stress gradient; CTA: computed tomography angiography; CLV: capacitance of left ventricle; CRV: capacitance of right ventricle; CPP: cerebral perfusion pressure; CVR: cerebral vascular resistance; ICP: intracranial pressure; TAWSS: time-averaged WSS; TCD: transcranial Doppler.

\section{Acknowledgements}

Great acknowledgement to the Support Plan for High-level Faculties in Beijing Municipal Universities (CIT\&TCD201804011) and the Beijing Excellent Talents Funds (2017000020124G277).

\section{Authors' contributions}

$B L$ designed the research approach, carried out the simulation experiments, analyzed the results and wrote the article. WW, BM and SC carried out some simulation experiments. HY revised the manuscript. YZ, JD and XL provided the physiological data. $\mathrm{HN}$ and $\mathrm{YL}$ were the subject guidance. All authors read and approved the final manuscript. 


\section{Authors' information}

Liu's group (Biomechanics Laboratory, Beijing University of Technology) has published researches on the numerical simulations of cardio-cerebrovascular hemodynamics by the geometric multiscale method in recent years. Their laboratory also focuses on the medical image processing.

Niu's group and their laboratory (Medical Instruments Laboratory, Beihang University) are mainly engaged in the development of medical instruments, modeling of bone and cartilage tissue, and ultrasound tissue imaging.

Dr. Du's group (EECP center, Sun Yat-sen University) focuses on the modeling and simulation of biomechanics, especially in the simulation and animal experiment of EECP.

\section{Funding}

This work was supported by the National Natural Science Foundation of China $(11832003,11772016,11472022$,

11702008); the Key Project of Science and Technology of Beijing Municipal Education Commission (KZ201810005007).

\section{Availability of data and materials}

The data were available.

\section{Ethics approval and consent to participate}

The study was approved by the Ethics Committee of The Eighth Affiliated Hospital, Sun Yat-sen University, and the clinical data were collected with the participants' consent.

\section{Consent for publication}

The authors agree this paper to be published.

\section{Competing interests}

The authors declare that they have no competing interests.

\section{Author details}

${ }^{1}$ Department of Biomedical Engineering, College of Life Science and Bioengineering, Beijing University of Technology, No. 100 Pingleyuan, Chaoyang District, Beijing 100124, China. ${ }^{2}$ Sino-Dutch Biomedical and Information Engineering School, Northeastern University, Shenyang 110004, China. ${ }^{3}$ School of Biological Science and Medical Engineering, Beihang University, Beijing 100083, China. ${ }^{4}$ The Eighth Affiliated Hospital, Sun Yat-sen University, Shenzhen 518033, China.

Received: 16 March 2019 Accepted: 16 August 2019

Published online: 28 August 2019

\section{References}

1. Ruangkanchanasetr P, Mahanonda N, Raungratanaamporn O, Ruckpanich P, Kitiyakara C, Chaiprasert A, Adirekkiat S, Punpanich D, Vanavanan S, Chittamma A, Supaporn T. Effect of enhanced external counterpulsation treatment on renal function in cardiac patients. BMC Nephrol. 2013;14:193.

2. Sharma U, Ramsey HK, TakT. The role of enhanced external counter pulsation therapy in clinical practice. Clin Med Res. 2013;11(4):226-32

3. Nanas JN, Moulopoulos SD. Counterpulsation: historical background, technical improvements, hemodynamic and metabolic effects. Cardiology. 1994;84(3):156-67.

4. Guluma KZ, Liebeskind DS, Raman R, Rapp KS, Ernstrom KB, Alexandrov AV, Shahripour RB, Barlinn K, Starkman S, Grunberg ID, Hemmen TM, Meyer BC, Alexandrov AW. Feasibility and safety of using external counterpulsation to augment cerebral blood flow in acute ischemic stroke-the counterpulsation to upgrade forward flow in stroke (CUFFS) trial. J Stroke Cerebrovasc Dis. 2015;24(11):2596-604.

5. Jungehuelsing GJ, Liman TG, Brunecker P, Ebel A, Endres M, Buschmann I, Pagonas N, Buschmann EE. Does external counterpulsation augment mean cerebral blood flow in the healthy brain? Effects of external counterpulsation on middle cerebral artery flow velocity and cerebrovascular regulatory response in healthy subjects. Cerebrovasc Dis. 2010;30(6):612-7.

6. Batysheva TT, Pivovarchik EM, Zaĭtsev KA, Kostenko EV, Kamchatnov PR, Boĭko AN. The first use of external counterpulsation for the rehabilitation treatment of post-stroke patients. Zhurnal Nevrologii i Psikhiatrii Imeni SS Korsakova. 2009;109(6):38-40.

7. Applebaum RM, Kasliwal R, Tunick PA, Konecky N, Katz ES, Trehan N, Kronzon I. Sequential external counterpulsation increases cerebral and renal blood flow. Am Heart J. 1997;133(6):611-5.

8. Zhang Y, He X, Chen X, Ma H, Liu D, Luo J, Du Z, Jin Y, Xiong Y, He J, Fang D, Wang K, Lawson W, Hui J, Zheng Z, Wu G. Enhanced external counterpulsation inhibits intimal hyperplasia by modifying shear stress responsive gene expression in hypercholesterolemic pigs. Circulation. 2007;116(5):526-34.

9. Pipp F, Boehm S, Cai WJ, Adili F, Ziegler B, Karanovic G, Ritter R, Balzer J, Scheler C, Schaper W, Schmitz-Rixen T. Elevated fluid shear stress enhances postocclusive collateral artery growth and gene expression in the pig hind limb. Arterioscler Thromb Vasc Biol. 2004;24(9):1664-8.

10. Samady H, Eshtehardi P, Mcdaniel MC, Suo J, Dhawan SS, Maynard C, Timmins LH, Quyyumi AA, Giddens DP. Coronary artery wall shear stress is associated with progression and transformation of atherosclerotic plaque and arterial remodeling in patients with coronary artery disease. Circulation. 2011;124(7):779-88.

11. Silver AE, Vita JA. Shear stress-mediated arterial remodeling in atherosclerosis: too much of a good thing? Circulation. 2006:113(24):2787-9.

12. Malek AM, Alper SL, Izumo S. Hemodynamic shear stress and its role in atherosclerosis. JAMA. 1999;282(21):2035-42.

13. Wentzel JJ, Chatzizisis YS, Gijsen FJH, Giannoglou GD, Feldman CL, Stone PH. Endothelial shear stress in the evolution of coronary atherosclerotic plaque and vascular remodelling: current understanding and remaining questions. Cardiovasc Res. 2012;96(2):234-43. 
14. Chatzizisis YS, Coskun AU, Jonas M, Edelman ER, Feldman CL, Stone PH. Role of endothelial shear stress in the natural history of coronary atherosclerosis and vascular remodeling: molecular, cellular, and vascular behavior. J Am Coll Cardiol. 2007:49(25):2379-93.

15. Speelman L, Teng Z, Nederveen AJ, Lugt AV, Gillard JH. MRI-based biomechanical parameters for carotid artery plaque vulnerability assessment. Thromb Haemost. 2016;115(03):493-500.

16. Ladisa JF, Bowers M, Harmann L, Prost R, Doppalapudi AV, Mohyuddin T, Zaidat O, Migrino RQ. Time-efficient patientspecific quantification of regional carotid artery fluid dynamics and spatial correlation with plaque burden. Med Phys. 2010;37(2):784-92.

17. Huang YN, Gao S, Li SW, Huang Y, Li JF, Wong KS, Kay R. Vascular lesions in Chinese patients with transient ischemic attacks. Neurology. 1997;48(2):524-5.

18. Dolan JM, Meng H, Singh S, Paluch R, Kolega J. High fluid shear stress and spatial shear stress gradients affect endothelial proliferation, survival, and alignment. Ann Biomed Eng. 2011;39(6):1620-31.

19. Xiong L, Han JH, Chen XY, Leung T, Soo Y, Leung H, Wong KS. Dynamic cerebral autoregulation and change of cerebral blood flow velocity in both MCAs in acute ischemic stroke during external counterpulsation. Int Symp Cereb Blood Flow Metab. 2009;29:S131.

20. Xiong L, Lin WH, Han JH, Chen XY, Leung T, Soo Y, Wong KS. A retrospective pilot study of correlation of cerebral augmentation effects of external counterpulsation with functional outcome after acute ischaemic stroke. BMJ Open. 2015;5(9):e009233.

21. Lin WH, Han JH, Chen XY, Xiong L, Leung H, Leung T, Soo Y, Wong KS. Predictors of good functional outcome in counterpulsation-treated recent ischaemic stroke patients. BMJ Open. 2013;3(6):e002932.

22. Lin WH, Xiong L, Han JH, Leung T, Soo Y, Chen XY, Wong KS. External counterpulsation augments blood pressure and cerebral flow velocities in ischemic stroke patients with cerebral intracranial large artery occlusive disease. Stroke. 2012:43(11):3007-11.

23. Lin W, Xiong L, Han J, Leung H, Leung T, Soo Y, Chen X, Wong KS. Increasing pressure of external counterpulsation augments blood pressure but not cerebral blood flow velocity in ischemic stroke. J Clin Neurosci. 2014;21 (7):1148-52.

24. Liang F, Oshima M, Huang H, Liu H, Takagi S. Numerical study of cerebroarterial hemodynamic changes following carotid artery operation: a comparison between multiscale modeling and stand-alone three-dimensional modeling. J Biomech Eng. 2015;137(10):101011.

25. Liang F, Takagi S, Himeno R, Liu H. Multi-scale modeling of the human cardiovascular system with applications to aortic valvular and arterial stenoses. Med Biol Eng Comput. 2009;47(7):743-55.

26. Vignon-Clementela IE, Figueroab CA, Jansen KE, Taylor CA. Outflow boundary conditions for 3D simulations of non-periodic blood flow and pressure fields in deformable arteries. Comput Methods Biomech Biomed Eng. 2010;13(5):625-40.

27. Cibis M, Potters WV, Gijsen FJ, Marquering H, Ooij PV, vanBavel E, Wentzel JJ, Nederveen AJ. The effect of spatial and temporal resolution of cine phase contrast MRI on wall shear stress and oscillatory shear index assessment. PLoS ONE. 2016;11(9):e0163316.

28. Taylor CA, Cheng CP, Espinosa LA, Tang BT, Parker D, Herfkens RJ. In vivo quantification of blood flow and wall shear stress in the human abdominal aorta during lower limb exercise. Ann Biomed Eng. 2002;30(3):402-8.

29. Li B, Chen S, Qi X, Wang W, Mao B, Du J, Li X, Liu Y. The numerical study on specialized treatment strategies of enhanced external counterpulsation for cardiovascular and cerebrovascular disease. Med Biol Eng Comput. 2018;56(11):1959-71.

30. Venuta ID, Boghi A, Gori F. Three-dimensional numerical simulation of a failed coronary stent implant at different degrees of residual stenosis. Part I: fluid dynamics and shear stress on the vascular wall. Numer Heat Transf Part A Appl. 2017;71(6):638-52.

31. Bai J, Wu D, Zhang J. A simulation study of external counterpulsation. Comput Biol Med. 1994;24(2):145-56.

32. Bai J, Ying K, Jaron D. Cardiovascular responses to external counterpulsation: a computer simulation. Med Biol Eng Comput. 1992;30(3):317-23.

33. Jaron D, Moore TW, Bai J. Cardiovascular responses to acceleration stress: a computer simulation. Proc IEEE. 1988;76(6):700-7.

34. Liang FY, Fukasaku K, Liu H, Takagi S. A computational model study of the influence of the anatomy of the circle of Willis on cerebral hyperperfusion following carotid artery surgery. BioMed Eng Online. 2011;10:84.

35. Zhao X, Liu Y, Li L, Wang W, Xie J, Zhao Z. Hemodynamics of the string phenomenon in the internal thoracic artery grafted to the left anterior descending artery with moderate stenosis. J Biomech. 2016;49(7):983-91.

36. Suga H, Sagawa K. Instantaneous Pressure-Volume relationships and heir ratio in the excised, supported canine left ventricle. Circ Res. 1974;35(1):117-26.

37. Stergiopulos N, Meister JJ, Westerhof N. Determinants of stroke volume and systolic and diastolic aortic pressure. Am Physiol Soc. 1996;270(6):2050-9.

38. Xing CY, Tarumi T, Liu J, Zhang Y, Turner M, Riley J, Tinajero CD, Yuan $\sqcup$, Zhang R. Distribution of cardiac output to the brain across the adult lifespan. J Cereb Blood Flow Metab. 2017;37(8):2848-56.

39. Schoning M, Walter J, Scheel P. Estimation of cerebral blood flow through color duplex sonography of the carotid and vertebral arteries in healthy adults. Stroke. 1994;25(1):17-22.

40. Bottom KE. A numerical model of cardiovascular fluid mechanics during external cardiac assist. Cambridge: Massachusetts Institute of Technology; 1999.

41. Michaels AD, Accad M, Ports TA, Grossman W. Left ventricular systolic unloading and augmentation of intracoronary pressure and Doppler flow during enhanced external counterpulsation. Circulation. 2002;106(10):1237-42.

42. Ozawa ET, Bottom KE, Xiao XS, Kamm RD. Numerical simulation of enhanced external counterpulsation. Ann Biomed Eng. 2001;29(4):284-97.

43. Chen DY, Tong CH, Liu KL. The method of tangent modulus factor for the design of external pressure vessels. Adv Mater Res. 2012;479-481:1578-84.

44. Callum KG, Thomas ML, Browse NL. A definition of arteriomegaly and the size of arteries supplying the lower limbs. Br J Surg. 1983;70(9):524-9.

45. Manning KB. Biofluid Mechanics: the human circulation. Cardiovasc Eng Technol. 2012;3(4):351-2. 
46. Qiao A, Zhang Z. Numerical simulation of vertebral artery stenosis treated with different stents. J Biomech Eng. 2014;136(4):1274-83.

47. Xiong L, Lin W, Han J, Chen X, Leung T, Soo Y, Wong K. Enhancing cerebral perfusion with external counterpulsation after ischaemic stroke: how long does it last? J Neurol Neurosurg Psychiatry. 2016;87:531-6.

48. Xiong L, Tian G, Lin W, Wang W, Wang L, Leung T, Mok V, Liu J, Chen X, Wong K. Is dynamic cerebral autoregulation bilaterally impaired after unilateral acute ischemic stroke? J Stroke Cerebrovasc Dis. 2017;26(5):1081-7.

49. CzarnikT, Gawda R, Kolodziej W, Latka D, Sznajd-weron K, Weron R. Associations between intracranial pressure, intraocular pressure and mean arterial pressure in patients with traumatic and non-traumatic brain injuries. Injury. 2009:40(1):33-9.

50. Giller CA, Bowman G, Dyer H, Mootz L, Krippner W. Cerebral arterial diameters during changes in blood pressure and carbon dioxide during craniotomy. Neurosurgery. 1993;32(5):737-42.

51. Shigemori M, Nakashima H, Moriyama T, Tokutomi T, Nishio N, Harada K, Kuramoto S. Noninvasive study of critical thresholds of intracranial pressure and cerebral perfusion pressure for cerebral circulation and brain function. Neurol Res. 1989;11(3):165-8.

52. Hu X, Xu P, Lee D, Vespa P, Baldwin K, Bergsneider M. An algorithm for extracting intracranial pressure latency relative to electrocardiogram R wave. Physiol Meas. 2008;29(4):459-71.

\section{Publisher's Note}

Springer Nature remains neutral with regard to jurisdictional claims in published maps and institutional affiliations.

- fast, convenient online submission

- thorough peer review by experienced researchers in your field

- rapid publication on acceptance

- support for research data, including large and complex data types

- gold Open Access which fosters wider collaboration and increased citations

- maximum visibility for your research: over 100M website views per year

At BMC, research is always in progress.

Learn more biomedcentral.com/submissions 